\title{
Helicobacter pylori gastric infection in patients with laryngeal cancer
}

\author{
Shih-Wei Lai ${ }^{1,2}$ (1) \\ Received: 17 January 2021 / Accepted: 20 January 2021 / Published online: 2 February 2021 \\ (c) The Author(s), under exclusive licence to Springer-Verlag GmbH, DE part of Springer Nature 2021
}

One cross-sectional study conducted by Pajić Matić et al. in European Archives of Oto-Rhino-Laryngology disclosed that there was a statistically significant association between laryngeal cancer and Helicobacter pylori infection [1]. Pajić Matić's study has attracted high attention and interest from scholars in the field of laryngeal cancer and Helicobacter pylori infection.

Some of my opinions are shared with the readers. First, the carcinogenic effects of smoking cigarettes and alcohol consumption on the development of laryngeal cancer have been well examined $[2,3]$. In addition, the evidence disclosed that a positive association was noted between current smoking and the prevalence of Helicobacter pylori infection [4]. To the contrary, moderate alcohol consumption might facilitate elimination of Helicobacter pylori infection [5]. Based on these studies, smoking and alcohol could confound the association between laryngeal cancer and Helicobacter pylori infection observed in Pajić Matić's study. However, the information on smoking cigarettes and alcohol consumption was not shown in Pajić Matić's study. If smoking cigarettes and alcohol consumption can be included for analysis, much evidence can be presented to the readers to clarify points in dispute. Second, the early symptoms of laryngeal cancer and Helicobacter pylori infection are subjective and variable. It is difficult to differentiate that laryngeal cancer or Helicobacter pylori infection occurs first. Therefore, the causal-effect relationship cannot be determined by a crosssectional study. Theoretically, the coexistence of laryngeal cancer and Helicobacter pylori infection observed in Pajić Matić's study is reasonable. I think that the observed association is true, but not causal. The current evidence is insufficient to regard Helicobacter pylori infection as a risk

Shih-Wei Lai

wei@mail.cmuh.org.tw

1 Department of Public Health in College of Public Health and School of Medicine in College of Medicine, China Medical University, Taichung, Taiwan

2 Department of Family Medicine, China Medical University Hospital, No 2, Yu-De Road, Taichung City 404, Taiwan factor for laryngeal cancer. Finally, the association between laryngeal cancer and Helicobacter pylori infection is novel, but related studies are not enough. More real-world data are needed to examine this association.

\section{Compliance with ethical standards}

Conflict of interest The author discloses no conflicts of interest.

\section{References}

1. Pajić Matić I, Matić I, Maslovara S, Veselski K, Stojadinović T, Vučković I (2021) Helicobacter pylori gastric infection in patients with laryngeal cancer and chronic laryngitis. Eur Arch Otorhinolaryngol 278(1):135-139

2. López-Abente G, Pollán M, Monge V, Martínez-Vidal A (1992) Tobacco smoking, alcohol consumption, and laryngeal cancer in Madrid. Cancer Detect Prev 16(5-6):265-271

3. Ramroth H, Dietz A, Becher H (2004) Interaction effects and population-attributable risks for smoking and alcohol on laryngeal cancer and its subsites. A case-control study from Germany. Methods Inf Med 43(5):499-504

4. Cardenas VM, Graham DY (2005) Smoking and helicobacter pylori infection in a sample of US adults. Epidemiology 16(4):586-590

5. Gao L, Weck MN, Stegmaier C, Rothenbacher D, Brenner H (2010) Alcohol consumption, serum gamma-glutamyltransferase, and helicobacter pylori infection in a population-based study among 9733 older adults. Ann Epidemiol 20(2):122-128

Publisher's Note Springer Nature remains neutral with regard to jurisdictional claims in published maps and institutional affiliations. 